\title{
Identification of naphthalene carboxylase subunits of the sulfate-reducing culture N47
}

\author{
J. S. Koelschbach · H. Mouttaki · J. Merl-Pham • M. E. Arnold • \\ R. U. Meckenstock
}

Received: 20 July 2018/ Accepted: 26 February 2019/Published online: 15 March 2019

(C) The Author(s) 2019

\begin{abstract}
Expanding industrialization and the associated usage and production of mineral oil products has caused a worldwide spread of polycyclic aromatic hydrocarbons. These pollutants accumulate and persist under anoxic conditions but little is known about the biochemical reactions catalyzing their anaerobic degradation. Recently, carboxylation of naphthalene was demonstrated for the sulfate-reducing culture N47. Proteogenomic studies on N47 allowed the identification of a gene cluster with products suggested to be involved in the initial reaction of naphthalene degradation. Here, we performed comparative proteomic studies with N47 proteins extracted from naphthalene versus 2-methylnapththalene-grown cells on blue native PAGE. The
\end{abstract}

Electronic supplementary material The online version of this article (https://doi.org/10.1007/s10532-019-09872-z) contains supplementary material, which is available to authorized users.

J. S. Koelschbach · M. E. Arnold .

R. U. Meckenstock ( $\bowtie)$

Biofilm Centre, Universität Duisburg-Essen, Essen,

Germany

e-mail: rainer.meckenstock@uni-due.de

J. Merl-Pham

Research Unit Protein Science, Helmholtz Zentrum

München, Neuherberg, Germany

J. S. Koelschbach · H. Mouttaki

Institute of Groundwater Ecology, Helmholtz Zentrum

München, Neuherberg, Germany analysis led to the identification of subunits of the naphthalene carboxylase of N47. Moreover, we show that the identified subunits are encoded in an operon structure within the previously mentioned naphthalene carboxylase gene cluster. These findings were supported by a pull-down experiment revealing in vitro interaction partners of a heterologously produced GST-tagged naphthalene carboxylase subunit. Based on these lines of evidence, naphthalene carboxylase is proposed to be a complex of about $750 \mathrm{kDa}$. Naphthalene carboxylase can be seen as a prototype of a new enzyme family of UbiD like de-/carboxylases catalyzing the anaerobic activation of non-substituted polycyclic aromatic hydrocarbons.

Keywords Prenylated flavin - Anaerobic hydrocarbon degradation $\cdot$ Sulfate reduction

\section{Introduction}

Polycyclic aromatic hydrocarbons (PAHs) are ubiquitous and persistent environmental pollutants originating from mineral oil products and spills, or from incomplete combustion. The high chemical stability and low aqueous solubility of PAHs make them very recalcitrant, especially in anoxic habitats (Meckenstock et al. 2016). Naphthalene represents the simplest polycyclic aromatic hydrocarbon and due to its 
relatively high solubility in water $\left(240 \mu \mathrm{M}\right.$ at $\left.25^{\circ} \mathrm{C}\right)$ compared to larger molecular weight PAHs, it is often used as a model compound for studying PAHs degradation. In the last two decades, microbial degradation of naphthalene was reported under sulfatereducing (Galushko et al. 1999; Meckenstock et al. 2000), iron-reducing (Kleemann and Meckenstock 2011; Lovley et al. 1994; Marozava et al. 2018), and methanogenic conditions (Christensen et al. 2004) (for review see Meckenstock and Mouttaki 2011).

Metabolite studies with sulfate-reducing cultures revealed 2-naphthoic acid as a potential intermediate of anaerobic naphthalene degradation and the incorporation of $\left[{ }^{13} \mathrm{C}\right]$ bicarbonate into the carboxyl group indicated a direct carboxylation of naphthalene (Meckenstock et al. 2000; Zhang and Young 1997). More reduced metabolites such as tetrahydro-2-naphthoic acid suggested a subsequent ring reduction to initiate ring cleavage (Meckenstock et al. 2000). Later, proteogenomic studies on the sulfate-reducing cultures N47 and NaphS2 allowed the identification of gene clusters specifically induced by growth with naphthalene as electron and carbon source (Bergmann et al. 2011b; DiDonato et al. 2010). Some of the gene products of one cluster exhibited strong similarity to a gene encoding ubiquinone decarboxylase UbiD of Escherichia coli and subunits of phenylphosphate carboxylase, one of the key enzymes in anaerobic phenol degradation (Bergmann et al. 2011b; DiDonato et al. 2010; Schühle and Fuchs 2004). Furthermore, the putative naphthalene carboxylase genes showed homology to genes putatively coding for the anaerobic benzene carboxylase detected in the iron-reducing enrichment culture BF (Abu Laban et al. 2010) (Fig. 1). Recently, Mouttaki et al. (2012) provided the first biochemical evidence confirming the naphthalene carboxylation reaction in the sulfate-reducing culture N47.

In order to identify the subunits of the naphthalene carboxylase protein complex, a recombinant production of the putative subunits was attempted in various E. coli strains with differing protein tags but yielded, for the most part, insoluble protein. During attempts to purify the naphthalene carboxylase complex under anaerobic conditions directly from N47 cells, all enzyme activity was lost (Kölschbach, unpublished results).

As such, it was unclear which of the gene products found to be differentially abundant in the naphthalene grown N47 culture, were involved in the naphthalene carboxylase protein complex (Bergmann et al. 2011b).

The aim of the present study was, thus, to identify which genes belong to the putative naphthalene carboxylase operon and which polypeptides constitute the naphthalene carboxylase protein complex of N47.

\section{Materials and methods}

Growth of culture N47 and preparation of cell-free extracts

The sulfate-reducing culture N47 was cultivated at $30{ }^{\circ} \mathrm{C}$ in serum bottles containing bicarbonate-buffered freshwater medium using naphthalene as carbon and electron source and sulfate as electron acceptor (Meckenstock et al. 2000). Naphthalene or 2-methylnaphthalene was added as a $1.5 \%(\mathrm{w} / \mathrm{v})$ solution in 2,2,4,4,6,8,8-heptamethylnonane $(20 \mathrm{~mL} / \mathrm{L}$ culture volume). For the preparation of cell-free extracts, cells were harvested by centrifugation $\left(3200 \times g, 4{ }^{\circ} \mathrm{C}\right.$, $30 \mathrm{~min}$ ) under anoxic conditions in an anaerobic chamber (Labstar, MBRAUN, Garching, Germany) under $100 \% \mathrm{~N}_{2}$ atmosphere. The anaerobic chamber, where all anaerobic experiments took place, is equipped with an internal $\mathrm{O}_{2}$ sensor to ensure that the oxygen concentration does not reach levels above $3 \mathrm{ppm}$. The cells were harvested in the mid-exponential growth phase, which had been determined in previous experiments (Meckenstock et al. 2000; Musat et al. 2009), after 6 weeks of cultivation. The cells were disrupted by 3-4 cycles of sonication (15-20 s/cycle; $30 \mathrm{kHz} ; 50 \%$ pulse; $40 \%$ amplitude; UP50H, Hielscher Ultrasonics GmbH, Teltow, Germany) in a pre-chilled metallic block followed by a 20 min centrifugation step $\left(13,000 \times g, 4{ }^{\circ} \mathrm{C}\right)$. The supernatant was amended with $1 \times$ complete protease inhibitor cocktail (Roche, Basel, Switzerland) to prevent protein degradation.

Operon mapping (transcriptional analysis)

\section{RNA extraction}

N47 cells were harvested by centrifugation of $150 \mathrm{~mL}$ culture. The cell pellets were resuspended in a buffer containing $50 \mathrm{mM}$ Na-Acetate, $\mathrm{pH} 5.3$ and $10 \mathrm{mM}$ Na-EDTA. RNA was extracted by bead beating in the 

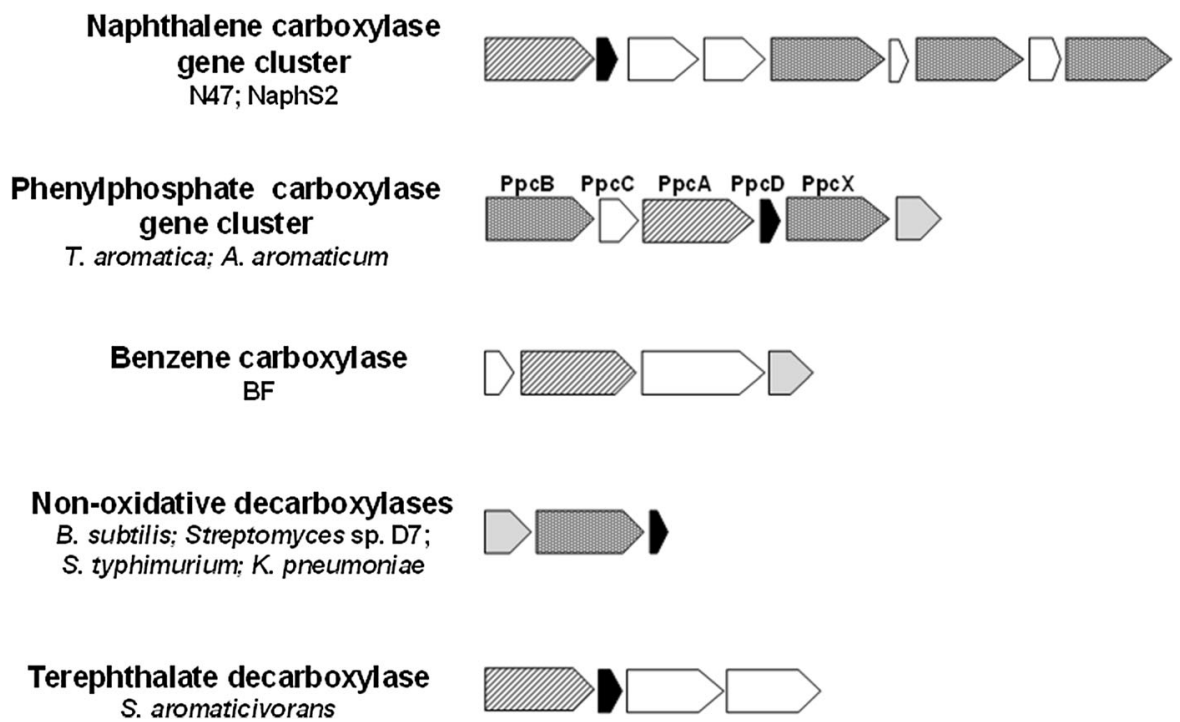

Fig. 1 Organization of gene clusters encoding UbiD-like proteins involved in anaerobic degradation of aromatic compounds. Open reading frames are represented by arrows. UbiDlike genes are shown in a pattern fill, whereas striped arrows

presence of sodium phosphate buffer and sodium dodecyl sulfate as reported by Schmitt et al. (1990). After centrifugation $\left(5 \mathrm{~min}, 13,000 \times g, 4{ }^{\circ} \mathrm{C}\right)$, the supernatant was extracted with equal volumes of phenol-chloroform-isoamylalcohol [24:24:1 (v/v/v)] and chloroform-isoamylalcohol $[24: 1(\mathrm{v} / \mathrm{v})]$ prior to precipitation ( $30 \mathrm{~min}, 13,000 \times g, 4{ }^{\circ} \mathrm{C}$ ) with $2 \mu \mathrm{L}$ glycogen (Roche, Basel, Switzerland) and 2 volumes of polyethylene glycol (Griffiths et al. 2000). Subsequently, the nucleic acid pellet was washed with $70 \%$ ethanol and resuspended in RNase-free water (Promega, Fitchburg, WI). The co-extracted DNA was digested with RQ1 RNase-free DNase (Promega, Fitchburg, WI) according to the manufacturer's instructions. The RNA was visualized by standard agarose gel electrophoresis and analyzed using NanoDrop (NanoDrop Technologies, Inc., Wilmington, DE) to estimate the quantity. RNA was stored at $-80{ }^{\circ} \mathrm{C}$ until further use.

\section{$R T-P C R$}

The RNA was reverse transcribed to cDNA by GoScript $^{\mathrm{TM}}$ reverse transcriptase using random hexamer primers $(0.5 \mu \mathrm{g} /$ reaction; Thermo Fisher Scientific, Waltham, MA) or gene-specific reverse primers (Table 1; 50199r, 48240r, 46360r, 44481r; 5 pmol represent $P p c A$-like genes. $P p c D$-like genes are indicated by dark grey and $U b i X$-like genes in light grey. Further details are mentioned in the text

each/reaction) as described by the manufacturer's protocol (Promega, Fitchburg, WI). These primers were designed manually and synthesized by Eurofins Genomics (Ebersberg, Germany). As negative controls, reactions were performed without the reverse transcriptase to detect eventual residual genomic DNA contamination.

\section{PCR amplification}

Intergenic regions were amplified via PCR using the primer sets listed in Table 1 with the following program: $5 \mathrm{~min}$ at $94{ }^{\circ} \mathrm{C}$ initial denaturation, 35 cycles of amplification $\left(30 \mathrm{~s}\right.$ at $94{ }^{\circ} \mathrm{C}, 15 \mathrm{~s}$ at $55^{\circ} \mathrm{C}$, $1 \mathrm{~kb} / 60 \mathrm{~s}$ at $72{ }^{\circ} \mathrm{C}$ ) and $5 \mathrm{~min}$ at $72{ }^{\circ} \mathrm{C}$ of final extension. The PCR reaction used $1 \times$ Taq PCR buffer, $1.5 \mathrm{mM} \mathrm{MgCl}_{2}, 0.2 \mathrm{mM}$ dNTPs, $0.5 \mu \mathrm{M}$ primer (Eurofins Genomics, Ebersberg, Germany) and 1.25 U Taq polymerase (Thermo Fisher Scientific, Waltham, MA).

\section{Cloning, production and purification of GST-NcA}

Genomic DNA from the sulfate-reducing culture N47 was extracted with the QIAamp DNA Mini kit (Qiagen, Hilden, Germany) as described by the manufacturer. Gene N47_K27540 encoding one of 
Table 1 Primer sets designed and utilized for transcriptional analysis (operon mapping)

\begin{tabular}{|c|c|c|c|}
\hline Primer set & Primer name & Sequence $\left(5^{\prime}-3^{\prime}\right)$ & Amplicon size (bp) \\
\hline \multirow[t]{2}{*}{$-\mathrm{A} 1$} & $53306 f$ & TATTAACGTAAAGGCAGGC & 1239 \\
\hline & $52068 \mathrm{r}$ & TTTCCAAGAGCTCAATAAACT & \\
\hline \multirow[t]{2}{*}{$-\mathrm{A}$} & $52641 \mathrm{f}$ & ATTATCAGAAGGGCTGTTTAA & 574 \\
\hline & $52068 \mathrm{r}$ & TTTCCAAGAGCTCAATAAACT & \\
\hline \multirow[t]{2}{*}{ A } & $50736 \mathrm{f}$ & AAAGATGTTCAGGAAAAGGT & 538 \\
\hline & $50199 \mathrm{r}$ & GCACTTCATCATGATGTTG & \\
\hline \multirow[t]{2}{*}{ B } & $49346 f$ & GAAGTACAGGAGGAGAAAGC & 1107 \\
\hline & $48240 r$ & CTTCATTGACTTCCACAAGT & \\
\hline \multirow[t]{2}{*}{$\mathrm{C}$} & $46832 \mathrm{f}$ & AGATCGACTGGCACAAGAAGT & 473 \\
\hline & $46360 \mathrm{r}$ & TGCGACATGGCACAGATAG & \\
\hline \multirow[t]{2}{*}{ D } & $45060 \mathrm{f}$ & TAGAGATCGTGTGGTGGCTTT & 580 \\
\hline & $44481 \mathrm{r}$ & TTCGCCTGAATGATTGAGG & \\
\hline \multirow[t]{2}{*}{ E } & $43268 f$ & AAGATAGGCTTGGATGCCAC & 913 \\
\hline & $42356 r$ & TCCAGGATAACACCCCTGATAT & \\
\hline \multirow[t]{2}{*}{ E1 } & $43268 f$ & AAGATAGGCTTGGATGCCAC & 496 \\
\hline & $42773 \mathrm{r}$ & GGTCGAGGTAACAATGCCTATT & \\
\hline \multirow[t]{2}{*}{ A1 } & pGEX6P1_SalI_52110f & GTAGTCGACTGATGGCGTTTAAAGATTTGAG & 1923 \\
\hline & $50199 \mathrm{r}$ & GCACTTCATCATGATGTTG & \\
\hline \multirow[t]{2}{*}{ B1 } & pGEX6P1_BamHI_50243f & GTAGGATCCATGGAAGAACGTGAAATACT & 1837 \\
\hline & $48416 \mathrm{r}$ & AAATCAATGACGCTCTTGCCTATCTT & \\
\hline \multirow[t]{2}{*}{$\mathrm{C} 1$} & $48303 \mathrm{f}$ & ATGGACACTAGAGAATTGGT & 1944 \\
\hline & $46360 \mathrm{r}$ & TGCGACATGGCACAGATAG & \\
\hline \multirow[t]{2}{*}{ D1 } & pGEX6P1_SalI_46472f & GTAGTCGACTGATGAGTTCATTAAGAGAA & 2003 \\
\hline & $44481 \mathrm{r}$ & TTCGCCTGAATGATTGAGG & \\
\hline
\end{tabular}

the naphthalene carboxylase subunits (NcA) (Bergmann et al. 2011b), was amplified from N47 genomic DNA using the primer set ncA_for (GTAGTCGACTGATGGCGTTTAAAGATTTGAG) and ncA_rev (GTAGCGGCCGCGAATCCATATTTATTCCAA TTG). The PCR product was purified using the PCRextract kit (5Prime, Hamburg, Germany) according to the manufacturer's protocol. Standard molecular cloning procedures were applied. Enzymes were purchased from Thermo Fisher Scientific. The amplicon was inserted into the expression vector pGEX-6P1 (GE Healthcare Europe, Freiburg, Germany) containing an IPTG-inducible lac-promotor and a GSTtag. Chemically competent $E$. coli Rosetta ${ }^{\mathrm{TM}}$ 2(DE3)pLysS (Merck, Darmstadt, Germany) were transformed with the plasmid pGEX-6P-1_ncA as described previously (Inoue et al. 1990). For production of the GST-tagged fusion protein GST-NcA, $1 \mathrm{~L}$ of LB-medium (Carl Roth $^{\circledR}$, Karlsruhe, Germany) containing ampicillin $(100 \mu \mathrm{g} / \mathrm{mL})$ was inoculated with the recombinant $E$. coli Rosetta $^{\mathrm{TM}}$ 2(DE3)pLysS including the plasmid pGEX-6P-1_ncA and incubated at $37{ }^{\circ} \mathrm{C}$. Gene expression was induced by addition of $0.5 \mathrm{mM}$ IPTG when the culture reached an optical density of 0.5 at $578 \mathrm{~nm}$, and the cells were shifted to room temperature for an additional $3 \mathrm{~h}$. The cells were harvested at $3200 \times g$ for $15 \mathrm{~min}$ at $4{ }^{\circ} \mathrm{C}$ and the pellet was stored at $-20{ }^{\circ} \mathrm{C}$ until further use. GST-NcA was purified using batch purification with Glutathione Sepharose $4 \mathrm{~B}$ beads as recommended by the manufacturer with the following modifications (GE Healthcare Europe, Freiburg, Germany). The stored pellet was resuspended in binding buffer $(50 \mathrm{mM}$ Tris/ $\mathrm{HCl}$, $\mathrm{pH} 7.5 ; 1 \mathrm{M} \mathrm{NaCl} ; 1 \mathrm{mM}$ EDTA) and the cells were disrupted by sonication as described above. After sonication, 1\% IGEPAL ${ }^{\circledR}$ CA-630 (Sigma-Aldrich, St. Louis, MO) was added. For purification, $1 \mathrm{~mL}$ of Glutathione Sepharose 4B slurry was used. The beads 
were incubated with $E$. coli Rosetta $^{\mathrm{TM}}$ 2(DE3)pLysS cell-free extract containing GST-NcA on an end-overend rotator at $4{ }^{\circ} \mathrm{C}$ for $2 \mathrm{~h}$ and subsequently 3 times washed with washing buffer $(50 \mathrm{mM}$ Tris/ $\mathrm{HCl}$, $\mathrm{pH} 7.5 ; 140 \mathrm{mM} \mathrm{NaCl}$ ). The GST-NcA coupled to the Sepharose beads was used for subsequent pulldown experiments. The purified protein was stored in $20 \mathrm{mM}$ Tris $/ \mathrm{HCl}$, pH 7.5 with $50 \%$ glycerol at $-20{ }^{\circ} \mathrm{C}$.

\section{In vitro protein interaction analysis (pull-down experiment)}

Purified GST-NcA coupled to the Glutathione Sepharose beads was washed with 1x PBS buffer $(140 \mathrm{mM}$ $\mathrm{NaCl}, 2.7 \mathrm{mM} \mathrm{KCl}, 10 \mathrm{mM} \quad \mathrm{Na}_{2} \mathrm{HPO}_{4}, 1.8 \mathrm{mM}$ $\mathrm{KH}_{2} \mathrm{PO}_{4}, \mathrm{pH} 7.3$ ) and $120 \mu \mathrm{L}$ of the slurry was incubated for $4 \mathrm{~h}$ at $4{ }^{\circ} \mathrm{C}$ with $500 \mu \mathrm{L}$ of the respective cell-free extract. After three washing steps $(1 \times$ PBS, $5 \mathrm{~min}, 4^{\circ} \mathrm{C}$ ), $30 \mu \mathrm{L}$ beads were combined with $5 \times$ SDS-PAGE loading dye and analyzed via SDS-PAGE. Protein bands were excised from the SDS-PAGE and submitted for proteomic analysis.

\section{Blue native PAGE}

Blue native PAGEs (BNPs) were performed in an anoxic chamber with $\mathrm{N}_{2}$-atmosphere using NativePAGE $^{\mathrm{TM}}$ Novex ${ }^{\circledR} 4-16 \%$ Bis-Tris gels in the XCell SureLock $^{\circledR}$ Mini Cell (Life Technologies, Carlsbad, CA, USA) according to the manufacturer's protocol. Activity of the naphthalene carboxylase was confirmed by an activity assay before samples were loaded on the gel. The activity assay contained a saturated naphthalene solution, $25 \mathrm{mM} \mathrm{NaHCO}$ and $5 \mathrm{mM}$ ATP in $100 \mathrm{mM}$ MOPS/KOH, $15 \mathrm{mM} \mathrm{MgCl}_{2}$, $\mathrm{pH} 7.3$ buffer. The assay was started by the addition of cell-free extract and stopped after 0, 15, 45, $90 \mathrm{~min}$ with $10 \%$ formic acid.

Proteomic analysis

\section{In-gel tryptic digest}

Coomassie-stained excised gel-pieces were digested as described previously (Merl et al. 2012). The eluted peptides were dried in a speed vac and stored at $-20{ }^{\circ} \mathrm{C}$ until further use.

\section{Mass spectrometric measurements}

Dried digested samples were thawed and dissolved in $45 \mu \mathrm{L}$ of $2 \%$ acetonitrile $/ 0.5 \%$ trifluoroacetic acid. After brief centrifugation $(13,000 \times g, 15 \mathrm{~min}), \mathrm{LC}-$ MS/MS analysis was performed on an Ultimate 3000 nano HPLC system (Dionex, Sunnyvale, CA) online coupled to a LTQ OrbitrapXL mass spectrometer (Thermo Fisher Scientific, Waltham, MA) by a nano spray ion source as described previously (Hauck et al. 2010; Merl et al. 2012). The samples were analyzed with and without the addition of dimethylsulfoxide (DMSO) to the buffers. Samples were loaded onto the C18 trap column at a flow rate of $30 \mu \mathrm{L} / \mathrm{min}$ in $7 \%$ acetonitrile $/ 0.1 \%$ formic acid (3\% buffer B $(73 \%$ $\mathrm{ACN} / 3 \% \mathrm{DMSO} / 0.1 \%$ formic acid (FA) in HPLCgrade water) and $97 \%$ buffer A (2\% ACN/3\% DMSO/ $0.1 \%$ FA)) (Hahne et al. 2013). After $5 \mathrm{~min}$, the peptides were eluted from the trap column and separated on the analytical column by a $135 \mathrm{~min}$ gradient from 7 to $32 \%$ acetonitrile in $0.1 \%$ formic acid (3 to $35 \%$ of buffer B) at $300 \mathrm{~nL} / \mathrm{min}$ flow rate followed by a short gradient from 32 to $93 \%$ acetonitrile in $0.1 \%$ formic acid ( 35 to $95 \%$ buffer B) in 5 min. Between each sample, the gradient was set back to $7 \%$ acetonitrile in $0.1 \%$ formic acid (3\% buffer B) and left to equilibrate for $20 \mathrm{~min}$.

From the MS pre-scan, the 10 most abundant peptide ions were selected for fragmentation in the linear ion trap if they exceeded an intensity of at least 200 counts and if they were at least doubly charged. During fragment analysis a high-resolution (60,000 full-width half maximum) MS spectrum was acquired in the Orbitrap with a mass range from 300 to 1500 Da.

\section{Label-free quantitative analysis}

The acquired raw data of each dataset was loaded in the Progenesis LC-MS software (version 2.5, Nonlinear) for label free quantification and analyzed as described previously (Hauck et al. 2010; Merl et al. 2012). Briefly, profile data of the MS scans were transformed to peak lists with respective peak $\mathrm{m} / \mathrm{z}$ values, intensities, abundances (areas under the peaks) and $\mathrm{m} / \mathrm{z}$ width. MS/MS spectra were treated similarly. After reference selection, the retention times of the other samples were automatically aligned to a maximal overlay of all features. Features with only one 
charge or more than seven charges were excluded from further analyses. After normalization and assignment of the samples to the respective groups, all MS/ MS spectra were exported as Mascot generic file (mgf) and used for peptide identification with Mascot (version 2.4) in the N47 protein database (version 4, 1302846 residues, 5001 sequences). Search parameters used were: $10 \mathrm{ppm}$ peptide mass tolerance and 0.6 Da fragment mass tolerance, one missed cleavage allowed, carbamidomethylation was set as fixed modification, methionine oxidation and asparagine or glutamine deamidation were allowed as variable modifications. Searches were performed with a Mascot ion score cut-off of 30 and an appropriate significance threshold $\mathrm{p}$, in order to reach a maximum false discovery rate of $1 \%$. Search results were reimported into the Progenesis LC-MS software. The abundances of all peptides allocated to each protein were summed up and exported. The resulting normalized protein abundances were used for calculation of fold-changes of proteins and for calculation of significance using an unpaired both-sided Student's $t$ test in Excel.

\section{Protein determination}

Protein concentrations were determined by the method of Bradford (1976) using Quick Start ${ }^{\mathrm{TM}}$ Bradford $1 \times$ Dye Reagent (Bio-Rad Laboratories, Hercules, CA) and bovine serum albumin as standard.

\section{SDS-PAGE}

SDS polyacrylamide gel electrophoresis was performed as described previously (gel concentration 15\%) (Laemmli 1970). PageRuler prestained protein ladder was used as a marker (Thermo Fisher Scientific, Waltham, MA).

\section{Results}

Determining the structure of the naphthalene carboxylase operon

Messenger RNA was extracted from N47 cells grown with naphthalene in order to identify genes of the putative naphthalene carboxylase gene cluster belonging to a transcriptional unit. The RNA was reverse transcribed into cDNA and PCR was performed using primers covering genes and/or intergenic regions to identify the potential operon (Table 1). Two genes were assigned to belong to the same operon (same mRNA) if a forward and a reverse PCR primer hybridizing to one of two adjacent genes, respectively, produced a PCR amplicon. Gene annotations were taken from Bergmann et al. (2011b). Amplicons were obtained between genes N47_K27540 and N47_K27520, N47_K27520 and N47_K27500, N47_K27500 and N47_K27480, and between N47_K27480 and N47_K27460. The PCR-products indicated that the naphthalene carboxylase gene cluster of strain N47 is transcribed as an operon of around $8.9 \mathrm{~kb}$ containing 9 genes from genes N47_K27540 to N47_K27460 (Fig. 2).

Determining the structure of the naphthalene carboxylase protein complex

Blue native PAGEs (BNPs) and LC-MS/MS analysis of the bands were performed to determine the size and polypeptide composition of the naphthalene carboxylase complex. Bands were excised from the gel and digested in-gel with trypsin. Then, the samples were dried and LC-MS/MS analysis was performed to determine the peptide composition of the different bands. The BNPs were performed under anoxic conditions to ensure that molecular oxygen did not impair the native conformation of the protein complexes.

Cell-free extracts of N47 cells grown with naphthalene exhibited a prominent band with a size of $750 \mathrm{kDa}$ (Fig. 3), which was not present in cells grown with 2-methylnaphthalene. Furthermore, two prominent bands of around $560 \mathrm{kDa}$ and $400 \mathrm{kDa}$ were more intense from cells grown with naphthalene (Fig. 3, Suppl. Table 1).

The three regions of the gels showing the differentially induced bands with sizes of about 750, 560, and $400 \mathrm{kDa}$ were excised and analyzed by label-free quantitative proteomics (Suppl. Table 2). The $750 \mathrm{kDa}$ band contained a total of 288 proteins, 29 of which were differentially abundant with a ratio of $\geq 2$ in cells grown with naphthalene compared to 2-methylnaphthalene (Suppl. Table 2A). The ratio was defined as the protein ratio calculated by normalized abundances from naphthalene to 2-methylnaphthalene samples. Furthermore, for identification a 

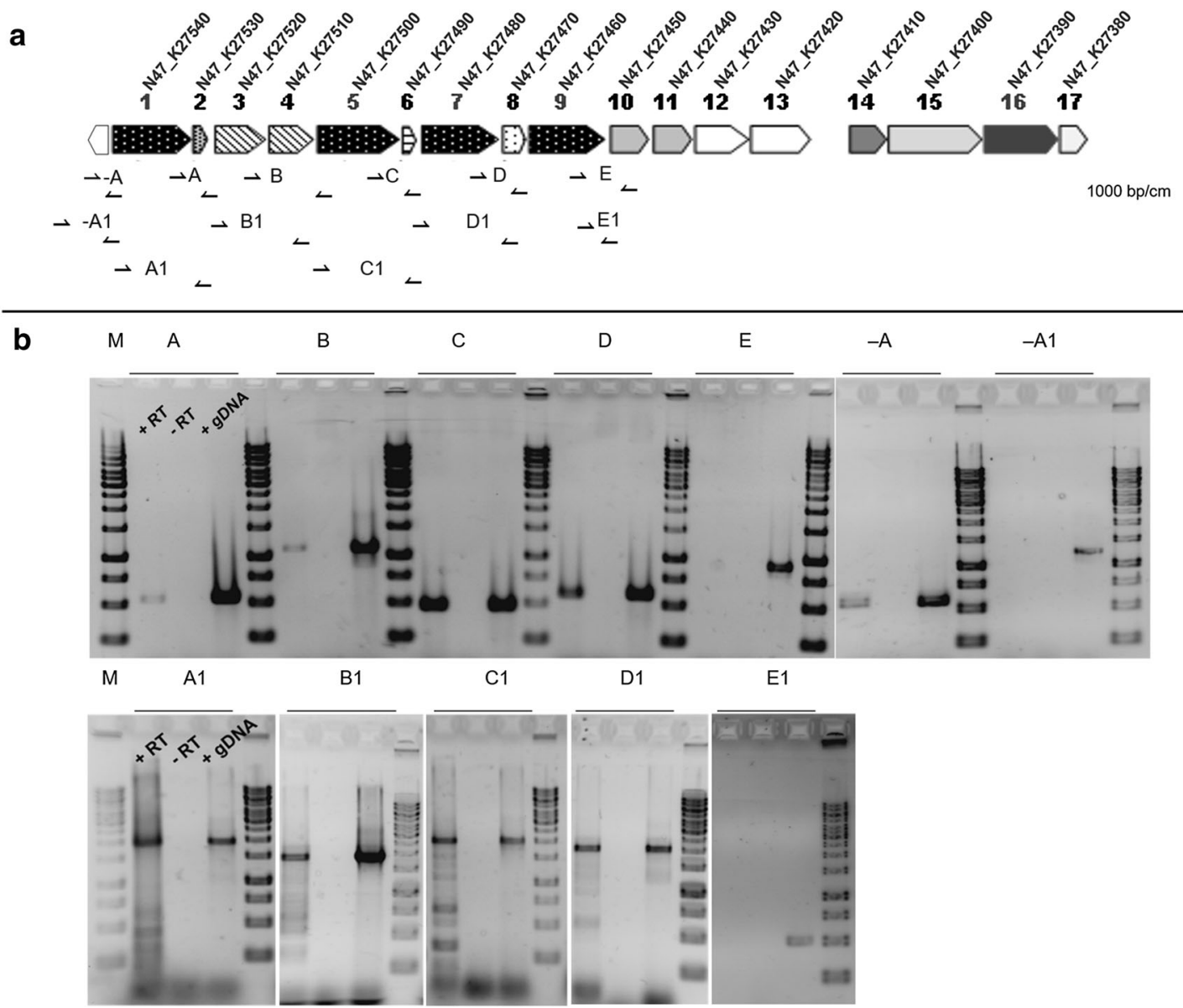

Fig. 2 a Organization of the gene cluster encoding enzymes potentially involved in the initial carboxylation reaction of naphthalene degradation in the sulfate-reducing Deltaproteobacteria N47 (GI:308273914 to GI:308273898). Open reading frames which products show similarity to UbiD-like carboxylases are filled in black, non-carboxylase-like subunits are shown in grey. Genes which are co-transcribed are indicated by a pattern fill. ORFs which products share high homology between the two strains have the same filling. Arrows represent primers used for transcriptional analysis by gene-specific PCR. Annotated function of the gene products: 1, putative phenylphosphate carboxylase, alpha subunit; 2, putative phenylphosphate carboxylase, gamma subunit; 3, MRP, Fer4_NifH superfamily; 4, ParA/MinD ATPase like, MRP, Fer4_NifH superfamily; 5, UbiD family decarboxylase; 6, conserved hypothetical protein; 7, UbiD family decarboxylase; 8, conserved hypothetical protein; 9, UbiD family

p-value of $\leq 0.01$ and a confidence score of $>30$ were applied as cut-off. In all three bands excised from the gel, the most abundant polypeptides were UbiD carboxylase-like gene products of the putative carboxylase gene cluster (Suppl. Table 2A-C). Almost decarboxylase; 10 \& 11, HAD hydrolase; 12 , membrane protein involved in aromatic hydrocarbon degradation; 13, IS4 transposase; 14, succinate dehydrogenase and fumarate reductase iron-sulfur protein; 15, putative succinate dehydrogenase flavoprotein subunit; 16, UbiD family decarboxylase; 17, pyridoxamine $5^{\prime}$-phosphate oxidase family protein. b Transcriptional analysis by RT- and subsequent gene-specific PCR. Results of gene-specific PCRs using three different templates per primer set. A $1.5 \%$ agarose gel stained with GelRed was used. M, DNA ladder; numbers, name of used primer set; lane 1, gene-specific PCR on cDNA template (addition of reverse transcriptase during cDNA synthesis); lane 2, control for potential genomic DNA contamination in cDNA template (no addition of reverse transcriptase during RT-PCR); lane 3, genespecific PCR on genomic DNA (positive control). Random hexamer primers were used in the RT-PCR

all of the gene products encoded in the naphthalene carboxylase operon were detected in the $750 \mathrm{kDa}$ protein complex. Only the gene product N47_K27460 was not found. This gene product showed high similarity to $\mathrm{PpcX}$, a phenol-induced UbiD like 


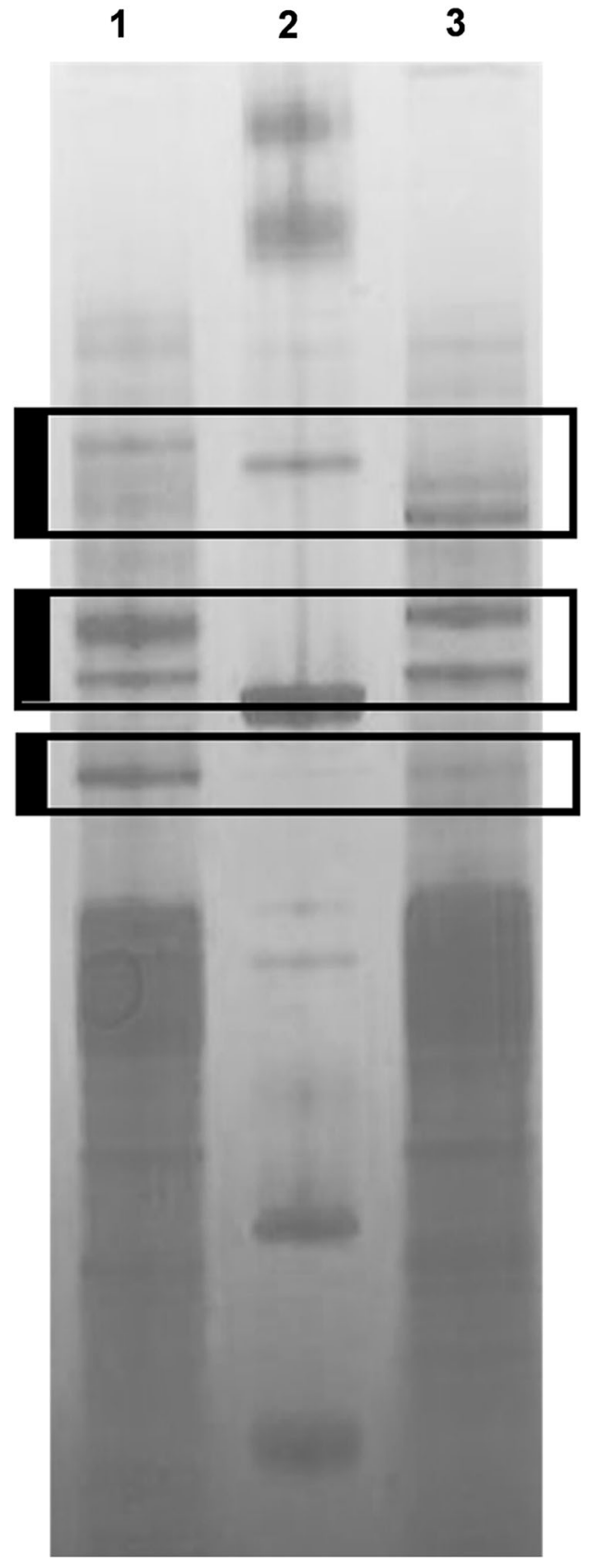

1236

1048

720

480

242

Fig. 3 Differential protein induction analysis of N47 on blue native PAGE. Boxes indicate slices of the gel which were cut out for proteomic analysis. Lane 1, cell-free extract of naphthalenegrown N47 cells; lane 2, molecular mass standard (1236-66 kDa); lane 3, cell-free extract of 2-methylnaphthalene-grown N47 cells

protein from $T$. aromatica and A. aromaticum, which is encoded in the phenol gene cluster but is not part of the phenylphosphate carboxylase complex (Schühle and Fuchs 2004). Three UbiD-like proteins N47_K27540 (52.4 kDa), N47_K27500 (57 kDa) and N47_K27480 (54.5 kDa) were part of the naphthalene carboxylase complex. Furthermore, N47_K27530 (9.8 kDa) which contained no conserved domains and the ParA/MinD ATPase-like proteins N47_K27510 (29.4 kDa) and N47_K27520 (33.6 kDa) were more abundant in naphthalene-grown N47 cells and therefore are proposed to represent subunits of the complex. Moreover, N47_K27490 $(9.2 \mathrm{kDa})$ as well as N47_K27470 (16.6 kDa) were identified and both annotated as hypothetical proteins.

In the $560 \mathrm{kDa}$ band, 23 proteins among 133 detected were differentially abundant with naphthalene as substrate (Suppl. Table 2B). The most abundant and differentially induced proteins were the carboxylase-like subunits N47_K27540, N47_K27500, N47_K27480 and N47_K27530 together with the heterodisulfide reductase subunits (N47_J04330, N47_J04340, N47J04350 and N47_ G39330, N47_G39340). Moreover, N47_E46900 a protein annotated as $\mathrm{K}(+)$-insensitive pyrophosphateenergized proton pump was detected and differentially produced.

In the $400 \mathrm{kDa}$ band, 10 polypeptides out of 125 detected were differentially abundant in naphthalenegrown cells (Suppl. Table 2C). The most abundant and at the same time differentially produced proteins were represented by the carboxylase-like proteins N47_K27500 and N47_K27480. The ATPase-like protein N47_K27520 as well as proteins annotated as heterodisulfide reductase subunits (N47_J04330, N47_J04340, N47J04350) were differentially abundant. The $\mathrm{K}(+)$-insensitive pyrophosphate-energized proton pump N47_E46900 was again identified.

In vitro protein interaction assays

In vitro interaction pull down assays were performed in order to identify subunits of naphthalene carboxylase interacting with the phenyl phosphate carboxylase (ppc)-like polypeptide N47_K27540 (Fig. 4, Suppl. Fig. 1), encoded by the first gene of the naphthalene carboxylase operon (Fig. 2a).

The most abundant proteins interacting with GSTNcA from naphthalene compared to 2-methylnaphthalene-grown cells were the carboxylase-like proteins N47_K27500 and N47_K27480 with enrichment factors of 23.6 and 31.0, respectively (Table 2A, B), 
and the two ATPase-like proteins N47_K27520 and N47_K27510 with enrichment factors of 50.4 and 56.2 (Table 2D). These proteins were also identified in the native conformation of the naphthalene carboxylase complex analyzed with blue native gels. Furthermore, the carboxylase-like protein N47_K27460 showed interaction with GST-NcA. The corresponding gene is also part of the naphthalene carboxylase operon but the polypeptide could never be detected in the blue native gels. Moreover, N47_K27400 a succinate dehydrogenase-like flavoprotein was identified in one of the sliced bands with an enrichment factor of 44.6 (Suppl. Table 1).

The genes of several other proteins which are not part of the naphthalene carboxylase gene cluster also interacted in the pull-down assay (Table 2). For example, N47_A07150, a FAD-binding domain protein, was enriched with a factor of 103.2 (Table 2C). Moreover, the ATPase-like protein N47_K27600, which was also detected in the $750 \mathrm{kDa}$ band of the blue native gels, interacted with an enrichment factor

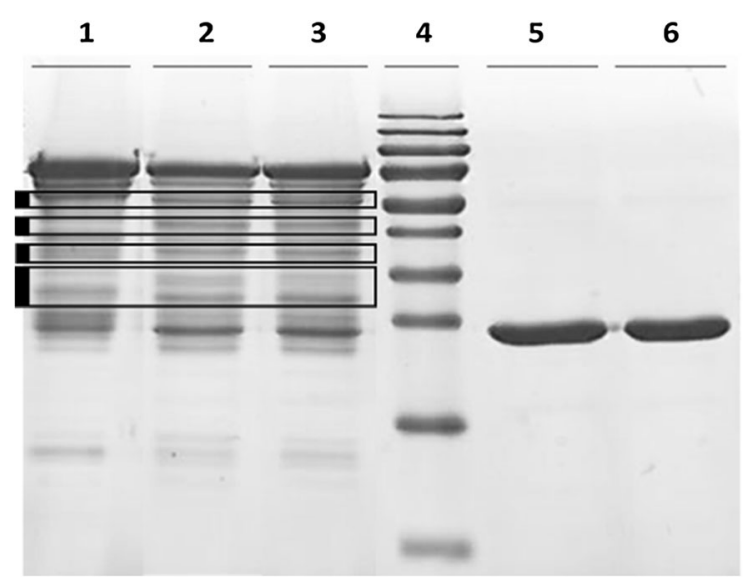

Fig. 4 SDS-PAGE of a protein interaction assay with GST$\mathrm{NcA}$ in cell-free extracts of N47 grown with naphthalene and 2-methylnaphthalene. Lane 1, purified GST-NcA coupled to glutathione Sepharose beads (input sample, $30 \mu \mathrm{L}$ ); lane 2, purified GST-NcA coupled to glutathione Sepharose after $4 \mathrm{~h}$ of incubation with cell-free extract of naphthalene-grown N47 cells (30 $\mu \mathrm{L})$; lane 3 , purified GST-NcA coupled to glutathione Sepharose beads (lane 1) after $4 \mathrm{~h}$ of incubation with cell-free extract of 2-methylnaphthalene-grown N47 cells (30 $\mu \mathrm{L})$; lane 4, molecular mass standard (170, 130, 100, 70, 55, 40, 35, 25, 15 and $10 \mathrm{kDa}$ ); lane 5, GST coupled to glutathione Sepharose beads after $4 \mathrm{~h}$ of incubation in cell-free extracts of naphthalenegrown N47 cells; lane 6, GST coupled to glutathione Sepharose beads after $4 \mathrm{~h}$ of incubation in cell-free extracts of 2-methylnaphthalene-grown N47 cells. Vertical boxes indicate parts of the gel which were cut and send for proteomic analysis of up to 84.9 (Table 2C, D). Furthermore, a sulfate adenylyltransferase (N47_J04360) showed an enrichment factor of 30.6 (Table 2D). This protein was not identified in the blue native gels but it is encoded in close vicinity to the putative heterodisulfide reductase subunits N47_J04330, N47_J04340 and N47_J04350, which showed up in naphthalene grown cells in the blue native gels.

\section{Discussion}

The carboxylation of naphthalene is an unprecedented biochemical reaction. In proteogenomic and transcriptomic analyses a conserved gene cluster encoding carboxylase-like proteins was identified in the sulfatereducing culture N47 (Bergmann et al. 2011b; DiDonato et al. 2010). Due to differential abundance with naphthalene, the gene products were proposed to be involved in the carboxylation of naphthalene. In the present study, we analyzed the structure of the respective operon and the composition of the naphthalene carboxylase protein complex.

Organization of the naphthalene carboxylase operon

The transcriptional analysis of the putative naphthalene carboxylase gene cluster revealed that the naphthalene carboxylase is transcribed as one operon ranging over 9 genes from N47_K27540 to N47_K27460. It contains the genes N47_K27540, N47_K27500,N47_K27480 and N47_K27460 encoding putative UbiD carboxylase like subunits. In E. coli, UbiD catalyzes the decarboxylation of an isoprenylated 4-hydroxybenzoate derivative in ubiquinone biosynthesis (Cox et al. 1969; Meganathan 2001). The identified subunits in N47 showed up to $46 \%$ sequence identity to the alpha subunit of the phenylphosphate carboxylase PpcA of T. aromatica and up to $48 \%$ to a putative anaerobic benzene carboxylase AbcA of the iron-reducing enrichment culture BF (Abu Laban et al. 2010; Schühle and Fuchs 2004). Two ParA/MinD ATPase-like proteins, N47_K27510 and N47_K27520, are encoded in the putative naphthalene carboxylase operon. Proteins with a ParA/MinD domain are involved in plasmid segregation and cell division (Gerdes et al. 2000) but are also found in iron-sulfur cluster biosynthesis 
Table 2 List of GST-NcA interacting polypeptides with an enrichment $\geq 15$ and a p-value $\leq 0.01$ detected in a pull-down assay and identified by LC-MS/MS

\begin{tabular}{|c|c|c|c|c|c|c|}
\hline $\begin{array}{l}\text { UniProtKB entry } \\
\text { name }\end{array}$ & $\begin{array}{l}\text { Peptides used for } \\
\text { quantitation }\end{array}$ & $\begin{array}{l}\text { Confidence } \\
\text { score }\end{array}$ & $\begin{array}{l}\text { Anova } \\
\text { (p) }\end{array}$ & Description & Annotated function & $\begin{array}{l}\text { ratio } \\
\text { Naph/ } \\
2 \mathrm{MN}\end{array}$ \\
\hline \multicolumn{7}{|l|}{ A. } \\
\hline E1YIW4_9DELT & 18 & 1162 & 0.000633 & N47_K27480 & UbiD family decarboxylase & 31.0 \\
\hline E1YIW6_9DELT & 13 & 819 & 0.000597 & N47_K27500 & UbiD family decarboxylase & 23.6 \\
\hline E1YIV6_9DELT & 14 & 855 & 0.001726 & N47_K27400 & $\begin{array}{l}\text { Putative succinate } \\
\text { dehydrogenase flavoprotein }\end{array}$ & 44.6 \\
\hline E1YAB2_9DELT & 4 & 217 & 0.000485 & N47_H23280 & $\begin{array}{l}\text { Fumarate hydratase class I, } \\
\text { anaerobic }\end{array}$ & 28.0 \\
\hline E1YAB2_9DELT & 4 & 217 & 0.000485 & N47_F14190 & $\begin{array}{l}\text { Uroporphyrin-III } \\
\text { C-methyltransferase }\end{array}$ & 155.1 \\
\hline E1YIW2_9DELT & 2 & 89 & 0.026798 & N47_K27460 & UbiD family decarboxylase & $\mathbf{5 1 7 1 . 5}^{a}$ \\
\hline \multicolumn{7}{|l|}{ B. } \\
\hline E1YKJ5_9DELT & 15 & 745 & 0.005969 & N47_E41400 & $\begin{array}{l}\text { Acetyl-CoA acetyltransferase/ } \\
\text { Thiolase }\end{array}$ & 17.1 \\
\hline E1YIW4_9DELT & 10 & 608 & 0.001111 & N47_K27480 & UbiD family decarboxylase & 16.7 \\
\hline \multicolumn{7}{|l|}{ C. } \\
\hline E1YIX6_9DELT & 6 & 305 & 0.006848 & N47_A07150 & FAD binding domain protein & $103.2^{a}$ \\
\hline E1Y816_9DELT & 5 & 213 & 0.002488 & N47_K27600 & $\begin{array}{l}\text { MinD ATPase like, Fer4_NifH } \\
\text { superfamily }\end{array}$ & 46.0 \\
\hline E1YFW1_9DELT & 2 & 65 & 0.009352 & N47_F14520 & CRISPR-associated protein & 21.3 \\
\hline \multicolumn{7}{|l|}{ D. } \\
\hline E1YIW7_9DELT & 21 & 1147 & 0.00746 & N47_K27510 & $\begin{array}{l}\text { MinD ATPase like, Fer4_NifH } \\
\text { superfamily }\end{array}$ & 56.2 \\
\hline E1YIW8_9DELT & 9 & 866 & 0.00195 & N47_K27520 & Fer4_NifH superfamily & 50.4 \\
\hline E1YFW1_9DELT & 9 & 392 & 0.00015 & N47_J04360 & Sulfate adenylyltransferase & 30.6 \\
\hline E1YIX6_9DELT & 7 & 323 & 0.00336 & N47_K27600 & $\begin{array}{l}\text { MinD ATPase like, Fer4_NifH } \\
\text { superfamily }\end{array}$ & 84.9 \\
\hline E1YFR3_9DELT & 4 & 153 & 0.00014 & N47_J03880 & $\begin{array}{l}\text { Putative electron transfer } \\
\text { flavoprotein, FixB }\end{array}$ & 25.8 \\
\hline
\end{tabular}

The proteins shown in bold letters, correspond to the ones which are encoded in the naphthalene carboxylase gene cluster. A. SDS gel region with a size of $60-50 \mathrm{kDa}$. B. SDS gel region with a size of 45-40 kDa. C. SDS gel region with a size of 38-35 kDa. D. SDS gel slice with protein size of $35-28 \mathrm{kDa}$

${ }^{\mathrm{a}}$ Coefficient of variation $(\mathrm{CV} \%) \geq 50$; in 2-methylnaphthalene samples

(ApbC/Nbp35 homologs). More recent studies showed that the ParA/MinD family is further involved in the positioning of large cytoplasmic protein complexes such as carboxysomes or chemotaxis clusters (Lutkenhaus 2012). A similar function of the proteins N47_K27510 and N47_K27520 is possible for the quite large carboxylase complex. Additionally, the genes N47_K27530,N47_K27490, and N47_K27470 annotated as hypothetical proteins are encoded within the naphthalene carboxylase operon. Due to the small size and the lack of conserved domains these genes might encode linker proteins of the naphthalene carboxylase complex.

Two subsequent genes were not part of the operon, N47_K27450 and N47_K27440. They are similar to genes coding for HAD-like polypeptides (cd01427; conserved domain database, National Center for Biotechnology Information) (Bergmann et al. 2011a; Selesi et al. 2010). The HAD-like superfamily is composed of hydrolases comprising phosphatases, 
among others. For example, the HAD-like protein $\mathrm{PpcC}$ is part of the phenylphosphate carboxylase in Thauera aromatica, a key enzyme in anaerobic phenol degradation (Schühle and Fuchs 2004). PpcC was proposed to bind and dephosphorylate the substrate phenylphosphate. As there was no indication for such a phosphorylated intermediate in the carboxylation of naphthalene, a phosphatase-like subunit might not be required in the functional naphthalene carboxylase complex.

Furthermore, the naphthalene carboxylase gene cluster was surrounded by viral genes in N47 (N47_K27300, N47_K27370, N47_K27640 putative transposases). Considering the high sequence similarity of the gene clusters and the presence of genetic elements which are involved in gene mobility, horizontal gene transfer of the genes for naphthalene degradation is likely.

Naphthalene carboxylase complex and its subunits

In comparative native proteomic studies with blue native gels, three prominent naphthalene-induced bands with a size of around 750, 560, and $400 \mathrm{kDa}$ were identified. Almost all polypeptides detected in the $750 \mathrm{kDa}$ band, which were differentially abundant with naphthalene versus 2-methylnaphthalene as growth substrate, were encoded in the naphthalene carboxylase operon. The prominent bands at 560 and $400 \mathrm{kDa}$ contained less polypeptides indicating disassociated sub complexes. This is supported by the fact that the $750 \mathrm{kDa}$ protein complex was only detectable from freshly harvested cells grown with naphthalene as carbon and electron source. The 750 $\mathrm{kDa}$ band was absent in 2-methylnaphthalene-grown cells where naphthalene carboxylase activity could hardly be detected. Thus, our indirect evidence indicates that the $750 \mathrm{kDa}$ band most likely represents the native naphthalene carboxylase complex. At the present state however, we were not able to purify an active naphthalene carboxylase enzyme complex. Considering the proteins contained in the $750 \mathrm{kDa}$ band, the native naphthalene complex putatively consists of three UbiD-like carboxylase subunits N47_K27540 (52.4 kDa), N47_K27500 (57 kDa) and N47_K27480 (54.4 kDa), the ParA/MinD ATPase-like proteins N47_K27510 (29.4 kDa) and N47_K27520 (33.6 kDa). Furthermore, the subunits N47_K27530 (9.8 kDa), N47_K27490 (9.2 kDa), and
N47_K27470 (16.6 kDa) are part of the naphthalene carboxylase complex as putative linker proteins.

Therefore, all subunits encoded in the naphthalene carboxylase operon, except for the carboxylase-like subunit N47_K27460, seem to be part of the naphthalene carboxylase complex. Our blue native gel experiments indicated that the naphthalene carboxylase complex has a size of around $750 \mathrm{kDa}$ in native conformation. If all the subunits encoded in the naphthalene carboxylase operon would be involved in the complex only once, it would have a size of around $314 \mathrm{kDa}$. Without the UbiD-like subunit N47_K27460, which might not be part of the naphthalene carboxylase, the complex is around $263 \mathrm{kDa}$.

Similar to the naphthalene carboxylase complex, the phenylphosphate carboxylase from $T$. aromatica represents a new type of UbiD-like carboxylase (Schühle and Fuchs 2004). The purified enzyme is composed of four subunits- of two UbiD-like proteins $(\alpha \beta, 54$ and $53 \mathrm{kDa})$, a hypothetical protein $(\gamma$, $10 \mathrm{kDa})$ and a phosphatase-like protein $(\delta, 18 \mathrm{kDa})$. The authors suggested a trimeric structure $(\alpha \beta \gamma \delta)_{3}$ for this carboxylase complex.

Assuming a similar trimeric structure analogous to the phenylphosphate carboxylase, the naphthalene carboxylase complex would have a molecular mass around $943 \mathrm{kDa}$ or $787 \mathrm{kDa}$ with or without N47_K27460, respectively. The latter matches the observed molecular mass of $750 \mathrm{kDa}$.

Interaction of naphthalene carboxylase with other proteins

The carboxylase-like protein N47_K27460 was encoded within the naphthalene carboxylase operon and an interaction with the other carboxylase-like proteins was shown in a pull-down assay, but it was not detected within the naphthalene-induced bands on BNPs. The interaction between the carboxylase complex and N47_K27460 could have either been destroyed during sample preparation or N47_K27460 is not part of the naphthalene carboxylase complex. The UbiD-like protein N47_K27460 was also not detected on 2D PAGEs (Bergmann et al. 2011b). In a phylogenetic tree of UbiD/PpcA-like subunits involved in anaerobic degradation of aromatic compounds, the protein formed a cluster with PpcX from T. aromatica and A. aromaticum strain EbN1 (Suppl. Fig/ 2, Suppl. Table 3). PpcX is a 
phenol-induced UbiD-like protein and its gene is encoded within the phenol gene cluster but it is not part of the phenylphosphate carboxylase complex (Schühle and Fuchs 2004).

Moreover, proteins which are annotated as heterodisulfide reductases were identified within the naphthalene-induced bands in BNPs. Heterodisulfide reductase-like proteins are also involved in anaerobic degradation of monoaromatic compounds. The BamDE subunits of the class II benzoyl-CoA reductase of Geobacter metallireducens share sequence similarity to heterodisulfide reductases (Fuchs et al. 2011; Kung et al. 2009). Here, benzoyl-CoA is reduced in an electron bifurcation process via ferredoxin $_{\text {red }}$ coupled to the exergonic reduction of $\mathrm{NAD}(\mathrm{P})^{+}$using another molecule of the same ferredoxin $_{\text {red. }}$. However, involvement of a reduction step to carboxylate naphthalene is not implicit and the appearance of heterodisulfide reductase-like proteins cannot be explained at the present state of knowledge.

UbiD-like (de)carboxylases involved in anaerobic degradation of aromatic compounds

In E. coli, the enzymes UbiD and UbiX facilitate the decarboxylation of 3-octaprenyl-4-hydroxybenzoate to 2-octaprenylphenol in ubiquinone biosynthesis (Gulmezian et al. 2007; Zhang and Javor 2003). Recently, UbiX and UbiD were identified as flavin mononucleotide (FMN) containing proteins working in a two-component system. UbiX synthesizes a prenylated FMN by adding a non-aromatic fourth ring to the flavin mononucleotide. UbiX enzyme activity is independent from metal cofactors and utilizes dimethylallyl-monophosphate as prenylating substrate (Payne KAP 2015; White et al. 2015). The prenylated FMNpr is transferred to UbiD, which performs the decarboxylation reaction.

In the N47 genome, a UbiX-like gene was not part of the naphthalene carboxylase cluster but two completely identical copies N47_B20630 and N47_H21380 were encoded elsewhere in the genome. In proteomic analyses, differentiation between these two proteins was not possible but one or both were differentially induced in cells grown with naphthalene.

At the present state of knowledge, the presence of a cofactor in the naphthalene carboxylase remains elusive. However, the amino acid sequences suggested potential binding sites for FMN in the carboxylase- like subunits N47_K27540, N47_K27500, N47_K27480, N47_K27460 (GO0010181; UniProtGO annotation database, European Bioinformatics Institute) and nucleotide-binding domains in the ATPase-like proteins N47_K27510 and N47_K27520 (cd02037; conserved domain database, National Center for Biotechnology Information).

Various UbiD-like (de)carboxylases involved in the degradation of aromatic compounds have been identified in recent years (Fig. 1). A gene cluster putatively encoding enzymes involved in the degradation of terephthalate was identified. One gene product showed similarity to an UbiD-like protein and was suggested to be a terephthalate decarboxylase (Lykidis et al. 2011; Wu et al. 2013). Therefore, analogous to the synthrophic, terephthalate-degrading Pelotomaculum spp. the authors proposed that terephthalate is first activated by a ligase and subsequently decarboxylated by a complex of an UbiD-like protein and a phenylphosphate $\gamma$-subunit-like protein to produce benzoyl-CoA. The UbiD-like subunit showed more than $40 \%$ sequence identity to N47_K27540. This reaction could recently be shown with phthalate as substrate in cell extracts of the strains Thauera, Azoarcus and 'Aromatoleum' (Ebenau-Jehle et al. 2017; Junghare et al. 2016).

\section{Conclusion}

Non-substituted PAHs like naphthalene need an initial activation in order to be further degraded. This first important reaction is carried out by a carboxylase in the case of naphthalene (Mouttaki et al. 2012). The naphthalene carboxylase complex consists of eight proteins, which are encoded in one operon. The protein N47_K27460 is also encoded in the operon but is not part of the complex. Comparison to the phenylphosphate decarboxylase suggests a similar trimeric structure for the naphthalene carboxylase complex with a size of $750 \mathrm{kDa}$. Three of the subunits building the protein complex were identified as UbiDlike proteins, putting the naphthalene carboxylase in the growing family of de-/carboxylases using a prenylated flavin cofactor.

Acknowledgements JSK was supported by the Deutsche Forschungsgemeinschaft (DFG) within the framework of the Priority Programme 1319 'Biological transformations of 
hydrocarbons without oxygen: from the molecular to the global scale'. The authors declare that there is no conflict of interest. RM acknowledges support by the ERC advanced grant EcOILogy \# 666952.

Open Access This article is distributed under the terms of the Creative Commons Attribution 4.0 International License (http:// creativecommons.org/licenses/by/4.0/), which permits unrestricted use, distribution, and reproduction in any medium, provided you give appropriate credit to the original author(s) and the source, provide a link to the Creative Commons license, and indicate if changes were made.

\section{References}

Abu Laban N, Selesi D, Rattei T, Tischler P, Meckenstock RU (2010) Identification of enzymes involved in anaerobic benzene degradation by a strictly anaerobic iron-reducing enrichment culture. Environ Microbiol 12:2783-2796

Bergmann F, Selesi D, Weinmaier T, Tischler P, Rattei T, Meckenstock RU (2011a) Genomic insights into the metabolic potential of the polycyclic aromatic hydrocarbon degrading sulfate-reducing Deltaproteobacterium N47. Environ Microbiol 13:1125-1137

Bergmann FD, Selesi D, Meckenstock RU (2011b) Identification of new enzymes potentially involved in anaerobic naphthalene degradation by the sulfate-reducing enrichment culture N47. Arch Microbiol 193:241-250

Bradford MM (1976) A rapid and sensitive method for the quantitation of microgram quantities of protein utilizing the principle of protein-dye binding. Anal Biochem $72: 248-254$

Christensen N, Batstone DJ, He Z, Angelidaki I, Schmidt JE (2004) Removal of polycyclic aromatic hydrocarbons (PAHs) from sewage sludge by anaerobic degradation. Water Sci Technol 50:237-244

Cox G, Young I, McCann L, Gibson F (1969) Biosynthesis of ubiquinone in Escherichia coli K-12: location of genes affecting the metabolism of 3-octaprenyl-4-hydroxybenzoic acid and 2-octaprenylphenol. J Bacteriol 99:450-458

DiDonato RJ Jr, Young ND, Butler JE, Chin K-J, Hixson KK, Mouser P, Lipton MS, DeBoy R, Methé BA (2010) Genome sequence of the deltaproteobacterial strain NaphS2 and analysis of differential gene expression during anaerobic growth on naphthalene. PLoS One 5:e14072

Ebenau-Jehle C, Mergelsberg M, Fischer S, Bruls T, Jehmlich N, von Bergen M, Boll M (2017) An unusual strategy for the anoxic biodegradation of phthalate. ISME J 11:224-236

Fuchs G, Boll M, Heider J (2011) Microbial degradation of aromatic compounds-from one strategy to four. Nat Rev Microbiol 9:803-816

Galushko A, Minz D, Schink B, Widdel F (1999) Anaerobic degradation of naphthalene by a pure culture of a novel type of marine sulphate-reducing bacterium. Environ Microbiol 1:415-420
Gerdes K, Møller-Jensen J, Jensen RB (2000) Plasmid and chromosome partitioning: surprises from phylogeny. Mol Microbiol 37:455-466

Griffiths RI, Whiteley AS, O’Donnell AG, Bailey MJ (2000) Rapid method for coextraction of DNA and RNA from natural environments for analysis of ribosomal DNA- and rRNA-based microbial community composition. Appl Environ Microbiol 66:5488-5491

Gulmezian M, Hyman KR, Marbois BN, Clarke CF, Javor GT (2007) The role of UbiX in Escherichia coli coenzyme Q biosynthesis. Arch Biochem Biophys 467:144-153

Hahne $\mathrm{H}$ et al (2013) DMSO enhances electrospray response, boosting sensitivity of proteomic experiments. Nat Methods 10:989-991

Hauck SM et al (2010) Deciphering membrane-associated molecular processes in target tissue of autoimmune uveitis by label-free quantitative mass spectrometry. Mol Cell Proteomics 9:2292-2305

Inoue H, Nojima H, Okayama H (1990) High efficiency transformation of Escherichia coli with plasmids. Gene 96:23-28

Junghare M, Spiteller D, Schink B (2016) Enzymes involved in the anaerobic degradation of ortho-phthalate by the nitratereducing bacterium Azoarcus sp. strain PA01. Environ Microbiol 18:3175-3188

Kleemann R, Meckenstock RU (2011) Anaerobic naphthalene degradation by Gram-positive, iron-reducing bacteria. FEMS Microbiol Ecol 78:488-496

Kung JW et al (2009) Identification and characterization of the tungsten-containing class of benzoyl-coenzyme A reductases. Proc Natl Acad Sci USA 106:17687-17692

Laemmli UK (1970) Cleavage of structural proteins during the assembly of the head of bacteriophage T4. Nature 227:680-685

Lovley DR, Woodward JC, Chapelle FH (1994) Stimulated anoxic biodegradation of aromatic hydrocarbons using Fe(III) ligands. Nature 370:128-131

Lutkenhaus J (2012) The ParA/MinD family puts things in their place. Trends Microbiol 20(9):411-418

Lykidis A et al (2011) Multiple syntrophic interactions in a terephthalate-degrading methanogenic consortium. ISME J 5:122-130

Marozava S, Mouttaki H, Muller H, Laban NA, Probst AJ, Meckenstock RU (2018) Anaerobic degradation of 1-methylnaphthalene by a member of the Thermoanaerobacteraceae contained in an iron-reducing enrichment culture. Biodegradation 29:23-39

Meckenstock RU, Mouttaki H (2011) Anaerobic degradation of non-substituted aromatic hydrocarbons. Curr Opin Biotechnol 22:406-414

Meckenstock RU, Annweiler E, Michaelis W, Richnow HH, Schink B (2000) Anaerobic naphthalene degradation by a sulfate-reducing enrichment culture. Appl Environ Microbiol 66:2743-2747

Meckenstock RU et al (2016) Anaerobic degradation of benzene and polycyclic aromatic hydrocarbons. J Mol Microbiol Biotechnol 26:92-118

Meganathan R (2001) Biosynthesis of menaquinone (vitamin $\mathrm{K}-2$ ) and ubiquinone (coenzyme Q): a perspective on enzymatic mechanisms. Vitam Horm 61:173-218 
Merl J, Ueffing M, Hauck SM, von Toerne C (2012) Direct comparison of MS-based label-free and SILAC quantitative proteome profiling strategies in primary retinal Müller cells. Proteomics 12:1902-1911

Mouttaki H, Johannes J, Meckenstock RU (2012) Identification of naphthalene carboxylase as a prototype for the anaerobic activation of non-substituted aromatic hydrocarbons. Environ Microbiol 14:2770-2774

Musat F et al (2009) Anaerobic degradation of naphthalene and 2-methylnaphthalene by strains of marine sulfate-reducing bacteria. Environ Microbiol 11:209-219

Payne KAP et al (2015) New cofactor supports $\alpha, \beta$-unsaturated acid decarboxylation via 1,3-dipolar cycloaddition. Nature 522:497-501

Schmitt ME, Brown TA, Trumpower BL (1990) A rapid and simple method for preparation of RNA from Saccharomyces cerevisiae. Nucleic Acids Res 18:3091-3092

Schühle K, Fuchs G (2004) Phenylphosphate carboxylase: a new C-C lyase involved in anaerobic in phenol metabolism in Thauera aromatica. J Bacteriol 186:4556-4567

Selesi D et al (2010) Combined genomic and proteomic approaches identify gene clusters involved in anaerobic 2-methylnaphthalene degradation in the sulfate-reducing enrichment culture N47. J Bacteriol 192:295-306

White MD et al (2015) UbiX is a flavin prenyltransferase required for bacterial ubiquinone biosynthesis. Nature 522:502-506

Wu J-H, Wu F-Y, Chuang H-P, Chen W-Y, Huang H-J, Chen S-H, Liu W-T (2013) Community and proteomic analysis of methanogenic consortia degrading terephthalate. Appl Environ Microbiol 79:105-112

Zhang H, Javor GT (2003) Regulation of the isofunctional genes $u b i D$ and $u b i X$ of the ubiquinone biosynthetic pathway of Escherichia coli. FEMS Microbiol Lett 223:67-72

Zhang X, Young LY (1997) Carboxylation as an initial reaction in the anaerobic metabolism of naphthalene and phenanthrene by sulfidogenic consortia. Appl Environ Microbiol 63:4759-4764

Publisher's Note Springer Nature remains neutral with regard to jurisdictional claims in published maps and institutional affiliations. 